\title{
Prophylactic versus postoperative antibiotics in septoplasty
}

\begin{tabular}{rr}
\hline Said Mustafa Jaf * & Sherzad Awla $* *$ \\
\hline \multicolumn{2}{c}{ Abstract }
\end{tabular}

Background and objective: Septoplasty is one of the most common procedures worldwide in otolaryngology clinics. The use of antibiotics in Septoplasty is a common practice among most otolaryngologists. However, there are few studies proving the efficacy, which is considered unnecessary by some others. This study aimed to compare the efficacy of prophylactic versus postoperative antibiotic in septoplasty and strengthen the evidence base for antibiotic use.

Methods: This prospective study was conducted on 90 patients that underwent septoplasty over six months period from August $1^{\text {st }}, 2012$ to January $31^{\text {st }}, 2013$ in Rizgary Teaching Hospital, Erbil city. They were equally divided into two groups; 45 patients in Group A and 45 patients in Group B. Their age ranged between 17-49 years old.

Results: No significant difference was observed in reduction of infection rate between Group A and Group B. No any statistically significant difference was found concerning pain, fever, purulent discharge and bleeding. Two of the patients (one from each group) developed septal hematoma.

Conclusions: Infection after septoplasty is rare and if occur is usually minor in nature. The outcome of postoperative antibiotic use does not outweigh that of a single prophylactic dose of antibiotic.

Keywords: Septoplasty; Infection; Prophylactic antibiotics.

\section{Introduction}

Difficulty in nasal breathing is probably the most common complaint in rhinologic practice. Among the major causes is nasal septum deviation (NSD), about $80 \%$ of the general population has a deviated nasal septum to some degree. ${ }^{1}$ For the purpose of diagnosis and documentation, as well as to correlate pathology with symptomatology, Cottle proposed in 1961 to divide the internal nasal cavity into the following five areas: ${ }^{1}$

Area 1: nostril (external ostium, naris), formed by the alar rim, the lateral border of the columella, and the floor of the vestibule. Area 2: the nasal valve area (internal ostium, isthmus).

Area 3: the area underneath the bony and cartilaginous vault (also called the "attic").

Area 4: the anterior half of the nasal cavity, including the heads of the turbinates and the infundibulum or osteomeatal complex.

Area 5: the posterior half of the nasal cavity, including the tails of the turbinates.

Septoplasty is one of the most common procedures in ear, nose, and throat clinics. ${ }^{2,3}$ The postoperative management is also highly variable with no accepted guidelines for many issues such as antimicrobial prophylaxis (AMP) versus no AMP . ${ }^{4}$ There is a distinction between the normal flora of the nasal vestibule and those of the nasal cavity concerning potential infectious pathogens (PIPs), in particular, Staphylococcus aureus. ${ }^{5,6}$ So far, only a few microbiological studies have been undertaken to differentiate the micro-organisms of the vestibule and cavity, although divergent bacterial colonization can be anticipated because

* Department of Surgery, College of Medicine, Hawler Medical University, Erbil, Iraq.

** Erbil Directorate of Health, Erbil, Iraq. 
the different linings of the vestibule and cavity constitute dissimilar microenvironments. Staphylococcus aureus resides predominately in the nasal vestibule and facial skin but is also present in $18 \%$ to $50 \%$ of microbiologic cultures from nasal mucosal smears of healthy subjects and is considered to be the most important PIP. ${ }^{7}$ Nasal bacterial flora primarily consists of diphtheroids, coagulase-negative cocci, and enterobacteria. The nose is a contaminated field; prophylactic antibiotics should be used to prevent devastating postoperative infections. ${ }^{8}$ The surgical procedures of airways/digestive tract are potentially considered as contaminated and may be associated with postoperative infectious complications. Because of this potential contamination, use of postoperative antibiotics at septoplasty is becoming more important. ${ }^{9}$ The most common complication of nasal surgeries is hemorrhage, with incidence rate between 0.7 to $3.6 \%$ of the cases. The second most common complication is infection. The use of antibiotics in otolaryngology is a common practice among most otolaryngologists, however, there are few studies proving the efficacy and the need for this practice, which is considered unnecessary by some authors. ${ }^{10,11}$ Prophylaxis is meant to augment host defenses at the time of bacterial invasion and is an attempt to attack organisms before any infection has occurred. ${ }^{4}$ Systemic antimicrobial prophylaxis is a potentially powerful preventive measure for surgical site infection (SSI) that is frequently delivered in an ineffective manner. It is clear that the administration of therapeutic doses of antimicrobial agents can prevent infection in wounds contaminated by bacteria sensitive to the agents. ${ }^{11}$ Choosing an antibiotic for prophylaxis is multifactorial and should be based on the type of operation, kinetics and toxicity of the drugs, microbiologic characteristics of the operative site and antibiotic sensitivities. ${ }^{4}$ Because of their broad antimicrobial spectrum and low incidence of allergic reactions, cephalosporins are the antimicrobials of choice for surgical procedures in which skin flora and normal flora of the gastrointestinal and genitourinary tracts are the most likely pathogens. Third-generation cephalosporins have an enhanced ability to resist hydrolysis by the $\beta$-lactamases of many Gram-negative bacilli. ${ }^{12}$ This study aimed to compare the efficacy of prophylactic versus postoperative antibiotic use in septoplasty and strengthen the evidence base for antibiotic use in septoplasty with the use of single parenteral injection of ciftrixone peroperativly versus cefixime $500 \mathrm{mg}$ orally once daily for five days.

\section{Methods}

This prospective study was designed and performed on 100 patients who underwent septoplasty surgery over a six months period from August $1^{\text {st }}, 2012$ to January $31^{\text {st }}, 2013$ in the Otolaryngology Department in Rizgary Teaching Hospital, Erbil city. Patients undergoing only septoplasty were included in the study. Only 90 patients were included in the study as ten patients were originally excluded from the study; 3 had nasal polyp, 2 undergone revision septoplasties, 2 undergone septorhinoplasties, and another 3 were septoplasty with submucous diathermy (SMD). Patients were selected for surgery based on clinical history, and otorhinolaryngological examination. All patients received general anesthesia and endotracheal intubation. Classical septoplasty was done by several otorhinolaryngologists. The patients were randomly divided into two groups; Group $A$ and Group B. The patients from Group A received oral antibiotic suprax (cefixime $400 \mathrm{mg}$ ) once daily for five days postoperatively and paracetamol tablet (500 mg) three times daily as pain killer, while those from Group B received only a single parenteral per-operative dose of ceftriaxone $1 \mathrm{~g}$ (enoxirt), and paracetamol tablet $(500 \mathrm{mg})$ three times 
daily as pain killer postoperatively. Both antibiotics are belonging to the $3^{\text {rd }}$ generation cephalosporins. The patients were given follow up appointments after discharging them from the hospital for:

At $3^{\text {rd }}$ postoperative day were observed for signs and symptoms such as fever, bleeding, pain, septal hematoma, and any other constitutional signs and symptoms as erythema, localized oedema and tenderness.

At $7^{\text {th }}$ postoperative day were re-evaluated for fever, bleeding, pain, amount of purulent nasal discharge, and any other constitutional signs and symptoms as erythema, localized oedema and tenderness.

At the $7^{\text {th }}$ postoperative day after removal of the splint, simultaneously swab was taken from nasal mucosa and sent for culture and sensitivity. The results of both groups A and B were compared.

The data were analyzed using the statistical package for the social sciences (version 18.0). Chi-square test of association was used to test the significance of association between knowledge and practices of participants with certain factors. A $P$ value of $\leq 0.05$ was considered as statistically significant.

\section{Results}

Ninety patients were included in the study, of which 61 patients were male, and 29 were female. Forty-five patients were allocated to Group A, and the rest of the patients were allocated to Group B. The mean age $( \pm S D)$ of the participants was $26.13 \pm 7.8$ years, ranging from 17 to 49 years. More than $50 \%$ of cases were within the age group 20-29 years. Sex distribution of patients was as follows: more than $2 / 3$ of the cases $(67.78 \%)$ were male, and $1 / 3(32.22 \%)$ were female. According to Cottle's classification, ${ }^{21}$ more than half $(58.9 \%)$ of our cases had moderately deviated septum, $30.0 \%$ had impacted septum, and only $11.1 \%$ had mildly deviated septum (Figure 1). Of 90 patients, only two patients (one in each Group) developed septal hematoma post-operatively at the end of first week (Table 1). Regarding signs and symptoms denoting infection (bleeding, pain, fever, mucopurulant discharge, and other constitutional symptoms) between the two groups at the end of $1^{\text {st }} 72$ hours and the end of $1^{\text {st }}$ week, no significant statistical difference was noted.

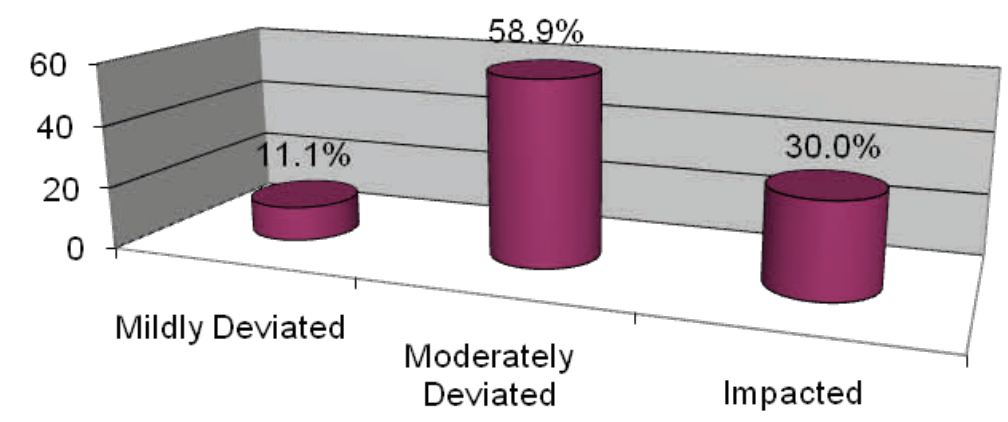

Figure 1: Distribution of sample according to severity of septal deviation.

Table 1: Number of patients with septal haematoma.

\begin{tabular}{llccc}
\hline Septal haematoma & & Group B & Group A & Total \\
\hline Septal haematoma at the end of $1^{\text {st }}$ 72 hrs & Yes & 0 & 0 & 0 \\
& No & 45 & 45 & 90 \\
Septal haematoma at the end of $1^{\text {st }}$ week & Yes & 1 & 1 & 2 \\
& No & 44 & 44 & 88 \\
\hline \hline
\end{tabular}


About $8.9 \%$ of patients in Group A 4 patients in Group A developed infection, developed infection at the end of $1^{\text {st }}$ post-operative week, while $6.7 \%$ developed infection in Group B at the end of $1^{\text {st }}$ postoperative week $(P=0.69)$. This difference was not statistically significant (Table 2). Concerning the relation between infection and the severity of septal deviation,

3 of them had impacted septum and only 1 had moderately deviated septum, while 3 patients in Group B developed infection and all had moderately deviated septum, but this difference was statistically not significant $(P=0.264)$ as shown in Table 3.

Table 2: Frequency distribution of signs and symptoms of infection between Group $A$ and Group B at the end of $1^{\text {st }} 72 \mathrm{hrs}$ and the end of $1^{\text {st }}$ week.

\begin{tabular}{|c|c|c|c|c|c|}
\hline \multirow{2}{*}{ Variables } & \multirow{2}{*}{ End of period } & \multicolumn{2}{|c|}{ Group } & \multirow{2}{*}{$\begin{array}{c}\text { Total } \\
\text { No. (\%) }\end{array}$} & \multirow{2}{*}{$P$ value } \\
\hline & & $\begin{array}{c}\text { Group A } \\
\text { No. (\%) }\end{array}$ & $\begin{array}{l}\text { Group B } \\
\text { No. (\%) }\end{array}$ & & \\
\hline \multirow{2}{*}{ Fever } & $1^{\text {st }} 72 \mathrm{hrs}$ & $2(4.4 \%)$ & $3(6.7 \%)$ & $5(5.6 \%)$ & \multirow{2}{*}{0.560} \\
\hline & $1^{\text {st }}$ week & $4(8.9 \%)$ & $3(6.7 \%)$ & $7(7.8 \%)$ & \\
\hline \multirow{2}{*}{ Pain } & $1^{\text {st }} 72 \mathrm{hrs}$ & $17(37.8 \%)$ & $18(4 \%)$ & $35(38.9 \%)$ & \multirow{2}{*}{0.890} \\
\hline & $1^{\text {st }}$ week & $6(13.3 \%)$ & $7(15.6 \%)$ & $13(14.4 \%)$ & \\
\hline \multirow{2}{*}{ Bleeding } & $1^{\text {st }} 72 \mathrm{hrs}$ & $0(0 \%)$ & $0(0 \%)$ & $0(0 \%)$ & \multirow{2}{*}{ NA } \\
\hline & $1^{\text {st }}$ week & $0(0 \%)$ & $0(0 \%)$ & $0(0 \%)$ & \\
\hline \multirow{2}{*}{ Mucopurulant discharge } & $1^{\text {st }} 72 \mathrm{hrs}$ & $2(4.4 \%)$ & $3(6.7 \%)$ & $5(5.6 \%)$ & \multirow{2}{*}{0.710} \\
\hline & $1^{\text {st }}$ week & $3(6.66 \%)$ & $1(2.2 \%)$ & $4(4.4 \%)$ & \\
\hline \multirow{2}{*}{$\begin{array}{l}\text { Other constitutional } \\
\text { symptoms }\end{array}$} & $1^{\text {st }} 72 \mathrm{hrs}$ & $6(13.33 \%)$ & $5(11.1 \%)$ & $11(12.2 \%)$ & \multirow{2}{*}{0.850} \\
\hline & $1^{\text {st }}$ week & $4(8.88 \%)$ & $4(8.9 \%)$ & $8(8.9 \%)$ & \\
\hline \multirow[t]{2}{*}{ Infection } & $1^{\text {st }} 72 \mathrm{hrs}$ & 0 & 0 & 0 & NA \\
\hline & $1^{\text {st }}$ week & $4(8.9 \%)$ & $3(6.7 \%)$ & $7(7.8 \%)$ & 0.690 \\
\hline
\end{tabular}

Table 3: Frequency distribution of infection according to severity of septal deviation.

\begin{tabular}{llccc}
\hline \multirow{2}{*}{ Group } & Severity of septal deviation/Group & $\begin{array}{c}\text { Proved infection in } \mathbf{1}^{\text {st }} \text { week } \\
\text { Yes } \\
\text { No. (\%) }\end{array}$ & $\begin{array}{c}\text { No } \\
\text { No. (\%) }\end{array}$ & $\begin{array}{c}\text { Total } \\
\text { No. (\%) }\end{array}$ \\
\hline Group A & Mildly Deviated & $0(0.0 \%)$ & $4(8.9 \%)$ & $4(8.9 \%)$ \\
& Moderately Deviated & $1(2.2 \%)$ & $23(51.1 \%)$ & $24(53.3 \%)$ \\
& Impacted & $3(6.7 \%)$ & $14(31.1 \%)$ & $17(37.8 \%)$ \\
Total & & $\mathbf{4 ( 8 . 9 \% )}$ & $\mathbf{4 1 ( 9 1 . 1 \% )}$ & $\mathbf{4 5 ( 1 0 0 . 0 \% )}$ \\
Group B & Mildly Deviated & $0(0.0 \%)$ & $6(13.3 \%)$ & $6(13.3 \%)$ \\
& Moderately Deviated & $3(6.7 \%)$ & $26(57.8 \%)$ & $29(64.4 \%)$ \\
& Impacted & $0(0.0 \%)$ & $10(22.2 \%)$ & $10(22.2 \%)$ \\
Total & & $\mathbf{3 ( 6 . 7 \% )}$ & $\mathbf{4 2 ( 9 3 . 3 \% )}$ & $\mathbf{4 5 ( 1 0 0 . 0 \% )}$ \\
\hline $\boldsymbol{P = 0 . 2 6 4}$ & \multicolumn{3}{|c}{} \\
\hline
\end{tabular}


Regarding swab cultures that have been taken at the end of $1^{\text {st }}$ week, $9(20 \%)$ cases in Group A showed growth of potentially infectious pathogen, twenty $(44.4 \%)$ of them showed normal bacterial flora (NBF), and $16(35.6 \%)$ showed no growth. In Group B, $11(24.4 \%)$ cases showed growth of PIP, $22(48.9 \%)$ cases showed NBF, and $12(26.7 \%)$ cases showed no growth (Figure 3).

\section{Discussion}

In this study, $8.9 \%$ of the patients from Group A developed infection, while 6.7\% of the patients from Group B developed infection. We didn't notice any significant increase in infection rate among patients receiving prophylactic antibiotics compared to those received postoperative antibiotics. Statistically, there was no any significant difference between Group A and Group B. In a study conducted by Andrews et al., the patients were randomized to two Groups; Group A received three $1200 \mathrm{mg}$ doses of intravenous amoxicillin-clavulanate. The first dose was given at induction of anesthesia, the second and third at 6 and 12 hours after surgery, respectively. Group B received $375 \mathrm{mg}$ of oral amoxicillin-clavulanate 3 times a day for seven days, starting after surgery. They found that $11 \%$ of patients who received postoperative antibiotics developed infection, and $7 \%$ of patients who received prophylactic antibiotics developed infection. This result was close to the result of our study. Regarding the analysis of the growth rate of bacteria postoperatively, our study did not show any significant difference between the two groups, and the most relevant PIP found, was Staphylococcus aureus. Celil GÖÇER et al. ${ }^{13}$ conducted a prospective study, in which patients were randomized into two groups; Group 1 were given postoperative antibiotic $375 \mathrm{mg}$ bid ampicillin-sulbactam for five days, and Group 2 were given a single preoperative dose of cefazolin $1 \mathrm{gr}$ intravenously 30 minutes before surgery. That study showed that the growth rate of bacteria was statistically taken into account rather than clinical signs of infection. They found that in the analysis of growth rates of bacteria there was no significant difference between the two groups, and the most commonly found PIP was Staphylococcus aureus in both groups. On the other hand, they stated that single dose prophylactic antibiotic didn't show more postoperative infection rates than that of the postoperative group. Only one in Group 1 (postoperative group) developed infection, and two in Group 2 (prophylactic group) developed infection. Their results were close to the results of our study, both from the clinical point of view and statistical analysis of growth rate of bacteria. Concerning postoperative pain, fever and purulent discharge, there was no apparent significant difference between Group A and Group B in our study pain, fever, purulent discharge. In a study conducted by Erkul et al., patients were randomly divided into two groups with a simple

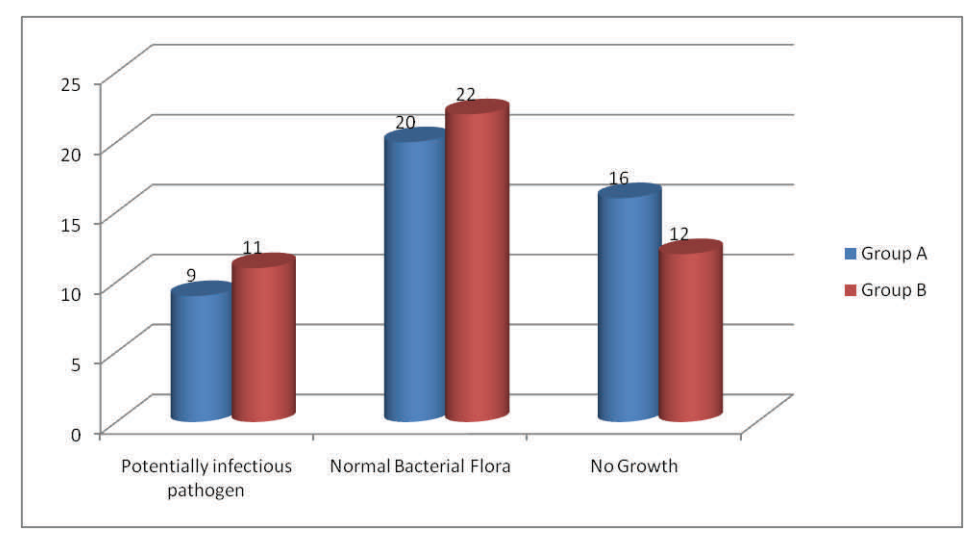

Figure 3: Number and types of bacteria found on swab cultures. 
randomization method. The first group of 80 patients received cephazolin, $1.0 \mathrm{~g}$ i.v. postoperatively once and the second group of 80 patients received amoxicillinclavulanate orally for seven days postoperatively (1000 mg every 12 hours). They followed up the patients on $1^{\text {st }}, 7^{\text {th }}$, and $14^{\text {th }}$ postoperative days. They found that there was no significant difference in postoperative pain between group $A$ and Group $B$ in $1^{\text {st }}$ day $(P=0.07)$; none of the patients presented any complaint related to pain in the follow-up appointment on $7^{\text {th }}$ and $14^{\text {th }}$ days postoperatively. Fever events also did not occur among patients. The rate of purulent discharge for Group A was $85.7 \%$ and for Group B was $68.6 \%$ on the $1^{\text {st }}$ day, three patients in group $A$ and three patients in group $B$ had moderate discharge on $7^{\text {th }}$ day. There was no difference related to the amount of purulent discharge on $14^{\text {th }}$ day postoperatively. In another prospective study conducted by Caniello et al., in which patients were randomized into 3 groups, Group A: without antibiotics; Group B antibiotic (cefazolin $1 \mathrm{~g}$ i.v.) only during the anaesthetic induction; Group C: antibiotic both in the anaesthetic induction (cefazolin $1 \mathrm{~g}$ i.v.) and postoperatively cephalexin orally for 7 seven days (500 mg every 6 hours) for seven days. All patients were followed up at interval 7 and 30 days after the surgery. They did not notice any significant difference among the groups concerning pain, fever, and purulent discharge. The results of the above two studies were close to the results of our study. Concerning postoperative septal hematoma, in this study two patients (one from each group) developed septal hematoma, both were drained and received antibiotic treatment and followed up for the next 7 days and had completely cured and developed no any sign of infection. Celil GÖÇER et al. found that two patients (one from each group) developed septal hematoma, both of them were treated and followed up after next 14 days and were infection free. This result was consistent with the result of our study.

\section{Conclusions}

Infection after septoplasty is rare and if occur is usually minor in nature. The outcome of postoperative antibiotic use does not outweigh that of a single prophylactic dose of antibiotic. No significant statistical difference was found in comparing the severity of septal deviation to infection rate.

\section{Conflicts of interest}

The authors report no conflicts of interest.

\section{References}

1. Alexander D, George F, Joanna M, Johannes Z, Heinrich I, George A. Septoplasty outcome in patients with and without allergic rhinitis. Rhinology 2009; 47:444-9.

2. Evren E, Mustafa B, Ozan K. Postoperative cephazolin usage is sufficient for preventing infection after septoplasty procedure. Allergy Rhinol 2011; 2.

3. Irfan K, Ahmet K, Turgut K, Sinasi Y, Erol K. Bacteriemia in septoplasty and septorhinoplasty surgery. Rhinology 2003; 41:76-9.

4. Rechtweg J, Paolini R, Belmont M, Wax M. Postoperative antibiotic use of septoplasty: a survey of practice habits of the membership of the American Rhinologic Society. Am J Rhinol 2001; 15(5):315-20.

5. Günaydın R, Aygenc E, Karakullukcu S, Fidan F, Celikkanat $S$. Nasal packing and transseptal suturing techniques: surgical and anaesthetic perspectives. Eur Arch Otorhinolaryngol 2011; 268:151-6.

6. Andrews P, East C, Jayaraj S, Badia L, Panagamuwa C, Harding L. Prophylactic vs Postoperative Antibiotic Use in Complex Septorhinoplasty Surgery. Arch Facial Plast Surg 2006; 8:84-7.

7. Ulrich G, Jan-Olaf G. The Nose As Bacterial Reservoir: Important Differences Between the Vestibule and Cavity. Laryngoscope, Philadelphia: Lippincott Williams \& Wilkins, Inc; 2000.

8. Jonathan P, Arlen D. Prophylactic Antibiotic Use in Head and Neck Surgery. 2012. (accessed on June at http://emedicine.medscape.com/ article/873812-overview)

9. Marcello, Gustavo H, Elder Y, Richard L, Ossamu B. Antibiotics in septoplasty: is it necessary? Brazilian Journal Of Otorhinolaryngology 2005; 71:734-8.

10. Teichgraeber J, Russo C. Treatment of nasal surgery complications. Ann Plast Surg 1993; 30:80-8.

11. Danyal A, Pachen E. Surgical Infections and Choice of Antibiotics. In: Townsend. Townsend: Sabiston Textbook of Suregry. 18th edition. New York: Saunders; 2007. PP. 264-79. 
Prophylactic versus postoperative antibiotics .......

Zanco J. Med. Sci., Vol. 20, No. (2), 2016

http://dx.doi.org/10.15218/zjms.2016.0027

12. Stoelting K, Hillier C. Handbook of Pharmacology and Physiology in Anesthetic Practice. $2^{\text {nd }}$ ed. New York: Lippincott Williams \& Wilkins; 2006. PP. 540-56.

13. Celil G, Engin D, Aydın A. antimicrobial prophylaxis in nasoseptal surgery. KBB-Forum 2007; 6:10-4 